\title{
Competencies for the Classroom Instructional Designer
}

\author{
Haidir Arafah, Ahmad Johari Bin Sihes \\ Faculty Education, University Technology Malaysia, Johor Bahru, Malaysia
}

Email adrress:

sarikong98@yahoo.com (H. Arafah),p-joha@utm.my (A. J. B. Sihes)

\section{To cite this article:}

Haidir Arafah, Ahmad Johari Bin Sihes. Competencies for the Classroom Instructional Designer. International Journal of Secondary Education. Vol. 3, No. 2, 2015, pp. 16-20. doi: 10.11648/j.ijsedu.20150302.11

\begin{abstract}
The aim of the present study is to identify the competence needed by secondary schools' teacher on designing their clasroom insruction. The study was conducted in the province of South Sulawesi Indonesia using qualitative approach. The respondent of the study is 8 persons, consists of school superintendent and teacher trainer selecting form several regencies. In order to find out the competences needed in term of competence in designing instruction, semi-structure interview was used in this study. The thematic analysis is used to get more detail information through indentifying, analysing,and reporting the pattern of competences needed. The research finding showed that there are four major competencies needed by socondary schools' teacher in designing their instruction, such as competence in subject matter, pedagogical, curriculum, and technology.
\end{abstract}

Keywords: Teachers' Competence, Instructional Design, Identify

\section{Introduction}

To be an effective teacher requires more than a sound of understanding of key concept and commitment to teach. The effectiveness of teaching is influenced by many aspects, teacher planning is regarding one of them. The effective teaching is determined by a good planning [1]. Instructional design is the description of the teaching and learning which will be conducted in classroom. Instructional design facilitates the students' needs and their achivement [2-3], social and cultural aspects as local context [4]. On the other words, a well instructional planning performs an interesting and effective teaching that regarding to the learner charateristics and their environment.

Most of the literature riviews stated that teacher is the main element in formulating and organizing the effective teaching. Regarding to the study of professor Jhon hattie cited by World Bank found that teacher influences the students' achivement around 30 percent [5]. Further, effective teacher affects the student achivement significantly [6-8]. It indicates that teacher is the person in charge of the succesful teaching and learning process

Previously, teacher used to teach regarding to the provided material, involved textbook. Teacher had been depended on the textbook as their guidance in their teaching process [9-11]. Consequently, the instructional process goes based on what the author wants in his textbook. It indicates that the lack of teachers' competence in designing their instruction. It caused by the lack of knowledge, skill, orientation, and concept to develop their instructions [12].

Instructional design not only for student purposes, but also provides more benefits for adult people who teach them [13]. Thus, it is important to identify the knowledge and skill needed as a part of enhancing teacher professional development particularly in designing intsruction.

\section{Competences in Designing Instructional}

Effective instruction requires a well development of the existing curriculum, especially the lesson plan. It will be more valuable if the their planning presenting with local context to bridge students' needs and their charateristics in to teaching and learning activities [12, 14]. Likewise, in context of planning and development of the classroom curriculum belongs to the teachers' responsibility [15].

Instructional design is the description of the teaching and learning process that related many aspects of life. As stated by [16]) that instructional design is the systematic organization on interpreting teaching and learning theories in planning teaching material and activities. Sequence of instructional material and effective use of instructional material regarding to the students' need and characteristics [17]. Thus, 
instructional design should fit the theory and models of instructional design and also teching and learning theories, the same way to the material selection should also match to the learner needs and characteristics.

The significance of identifying teachers' competence in term of intsructional design regarding to enhance teacher and school development. There are several studies had been conducted relating the instructional design competence, as follows:

The importance of subject matter comprehension for teachers will affect to their efforts, such level of confidence and the way he teaches in a particular subjects. As the findings of the study conducted by [18-20] found that comprehending the various aspects of the subject, such conception of the subject, the subject structure, the level of difficulty of subject content will facilitate student ability with the strong foundation on their subject understanding, and promote meaningful learning

[21] conducted a study on the ability of English teacher in designing instruction, found that the importance of pedagogical competence to achieved meaningful teaching and learning. In line with, [22] conducted his study on teachers' decision-making in developing curriculum and instruction, found that decision-making become an important skill for teacher in relating to interpret the intended curriculum into the taught curriculum.

Another competence proposed by, [23] in his study on integrating Information Communication and Technology (ICT) and pedagogical in 22 countries, found that teachers' perception on integrating ICT in teaching and its planning plays significant influence toward the students' motivation and achievement. Attracting students' attention, facilitating students' learning process, helping to improve students' vocabulary knowledge and promoting meaningful learning [24]. Improvement to the clarity of information that provided to students and gives more chance to the students with interesting and enjoying teaching activities [25]. Therefore, the implementation of the ICT into the instruction and its planning gives much advatages for the students' motivation and achievement.

\section{Problem Statement}

A well instructional planning will perform the effective teaching. It consists of various activities that regarding to the students' needs and characteristics, beside it, careful and meaningful selection of teaching material, teaching method and includes the interesting media will promote effective instructional design. However, in fact mostly instructional planning is made just to fulfill the administrative requirement when teacher is being supervised. It is not designed to be a guidance of the instructional process. Consequently, most of the teachers took the easiest way through "copy and paste" form their friends. Therefore, the study aims to identify the competence needed in designing instruction by formulating research question, as follows: What is the competence needed by teacher in designing instruction?

\section{Methodology}

The study was conducted in qualitative through semi-structure interview. The study was conducted in Makassar, Indonesia in 2013. The study involved 8 respondents consisted of school superintendent and teacher trainer, they were selected as respondent using snowball sampling to be interviewed. To ensure the confidentiality of the identity of the respondents, the researcher used coding like $\mathrm{P} / \mathrm{L} / 01$ to the respondents and $\mathrm{P} / \mathrm{L} / 01$ to interview respondents. "P" is a school superintendent, "GI is the teacher trainer code", and " $\mathrm{L}$ " is Laki-laki or sex. While " 01 " refers to the respondent. Thematic analysis was utilized in term of data analyze. In this study, the thematic analysis process refers to [26] it has five steps, such as familiarising with data, generating initial codes, searching for themes, riviewing themes, and defining and naming themes.

\section{Finding and Discussion}

The study found four categories of competence, such as: pedagogical competence, subject matter competence, curriculum competence, and technological competence. Those categories depeloved from the analysis of the interviews both schoool superintendent and teacher trainer, as follows.

\subsection{Pedagogical Competence}

$\mathrm{P} / \mathrm{L} / 01$ said that there are many aspects should be mastered in designing the instruction. He adds it is regarding to the whole of the dimension of the teaching and learning process. $\mathrm{P} / \mathrm{L} / 01$ opinion was supported to by $\mathrm{GI} / \mathrm{W} / 03$. G/I/W/03 claimed that instructional design consists of the implementation of the teaching and learning theories. GI/W/03 mentioned that:

....planning a good intrsutional design will give an interesting teaching environment and positive impact to students..through a weel instructional planning, teacher will be easier to arrange the teaching method and material... in selecting the teaching method and material, teacher should consider the learner characterics.. (GI/W/03).

$\mathrm{P} / \mathrm{L} / 02$ completes the GI/W/03 opinion in to be more detail explanation. He expresses that instructional design is the process of thinking toward how the efective teaching will be taking place. $\mathrm{P} / \mathrm{L} / 02$ said that:

..planning is a process or the way we are thinking to reach the result the we expected before. In addition, it becomes an anticipation and approximation toward the process that will be apllied during the teaching, to acquire the the learning objectives. Therefore we should implement the teaching principles throuh teaching activities, planning it self, implementation, and evaluation in order to achieved the learning objectives that we had been decided before.. (P/L/02). 


\subsection{Subject Matter Competence}

$\mathrm{P} / \mathrm{W} / 03$ stated that teacher should posed the a lot of knowledge in order to enrich their instructional design. $\mathrm{P} / \mathrm{L} / 04$ added that the more knowledge or information of the teacher owned the better planning will be produced. $\mathrm{P} / \mathrm{L} / 04$ stated that:

....... as a teacher profession...we have to know more than our students...we have to know a lot things which can be derived from many sources, such newspaper, television and internet. to increase our knowledge...and ithink it will support in my teaching and its planning.. (P/L/04).

GI/L/02 stated that instrudtional planning should be contextually. It means that teacher plans the instruction based on their local context. $\mathrm{P} / \mathrm{W} / 03$ exlored more elements that related to the local context. $\mathrm{P} / \mathrm{W} / 03$ expressed that:

......on the latest curriculum recommends teacher to integrate the local content into the instructional planning. Because, our country has a lot of culture, every tribe have their own culture, language, and local wisdom. These are uniques things, that could not be found in other countries. Therefore, this curriculum provides a space for local content integration. For example, i'm english teacher...i can use the folklore related to my tribe which is familiar for the my students, then $i$ presented in english as reading material... $(P / W / 03)$.

\subsection{Curriculum Competence}

Curriculum competences include the ability to synergize the target of curriculum and the needs of education stakeholders in instructional design. GI/L/02 noted the importance of the curriculum competence as follows:

........as teachers , we have to know before learning begins ... we must create the instructional planning which consists of annual programs that contains annual teaching planning, then Semester programs teaching preparation for one semester and lesson plan... ee .. The instructional design refers to the syllabus and fit to the academic calendar, the schedule of subjects and facilities available at the school. Subsequently, sir, ...instructional planning is the factor that supports the learning conditions in the classroom that contains a series of learning events conducted by a group of students. (GI / L / 02).

Based on the interview (GI / L/ 02) shows that curriculum competence encompass many aspects. Planning consists of various elements of learning is begun from annual program that contains one year teaching planning relating to the existing curriculum. Then semester program is the teaching and learning plan for a single semester purpose. Lesson plan is the planning for teaching on each day that refers to units, topics, and themes of learning that are tailored to the syllabus. Formulating evaluation system in order to measure the teaching and learning process. for GI / W / 04 add on the importance of the curriculum knowledge, as follows:
...... that the things need to be prepared by teacher is to analyze the existing syllabus, so according me that national education goals is first step, because it is main core of the education target is to achieve national education goals, so the first thing to note is the national education goals. Then ... eeee...teacher elaborating national education goals into learning objectives....so teachers must be able to understand the objectives of the national education goals. ( $G I / W / 04)$.

The interview (GI / W / 04) discussed aspects of curriculum knowledge includes teachers' understanding of the goals of national education. Comprehend the national education goal will led teacher into better interpretation on it. Therefore, the national education goals should be transform into learning objectives and formulating the indicators for each objectives, thus teaching activities should achieve the national education goals.

\subsection{Technological Competence}

Technological competence becomes important skill for teachers today. It is caused by the flow of information technology development is very fast and it affects all aspects of human life, including education. P / L / 01 point about the importance of knowledge technologies (ICT) as follows:

...... the advantages of computers and the internet is helping teachers in a variety of tasks, such as designing instruction, making lesson plans, making teaching materials, create instructional media, and design the evaluation ....eee...so...it is not difficult thing, like in the past, it used to be handwritten on planning the instruction.. (P/L/01).

According to the interviewee ( $\mathrm{P} / \mathrm{L} / 01)$ above that technological devices may help teachers arranging their work effectively, such as planning, implementation, and evaluation of learning. In term of planing their lesson, teacher may search their materials from the internet, design interesting media using computer as well as establishing such online test as a part of evaluation. In addition, the P / L / 04 added the advantages technology, as follows:

..... the varied of teaching methods will avoid student bored to learn ....... diversity of learning methods can be obtained from such technological media, such as you tube. (P / L / 04).

Regarding to the interview $\mathrm{P} / \mathrm{L} / 04$ that the integration of ICT enhances teaching and learning environment with variety of activities, such as searching some interesting teaching methods, medias, and evaluation system . It can be obtained from the internet for example you tube and many other websites. Through you tube we can find a lot of teaching method videos and media that posted to the internet, teacher may select based on their needs. It may be concluded that mastering technology is a helpful skill for teachers in performing teaching and learning interactively with a variety 
of learning activities, varied methods, interesting media, as well as the effectiveness and interesting subject matter presentation.
The tables below is the result of the interview analysis using thematic analysis.

Table 1. Thematic Analysis Result

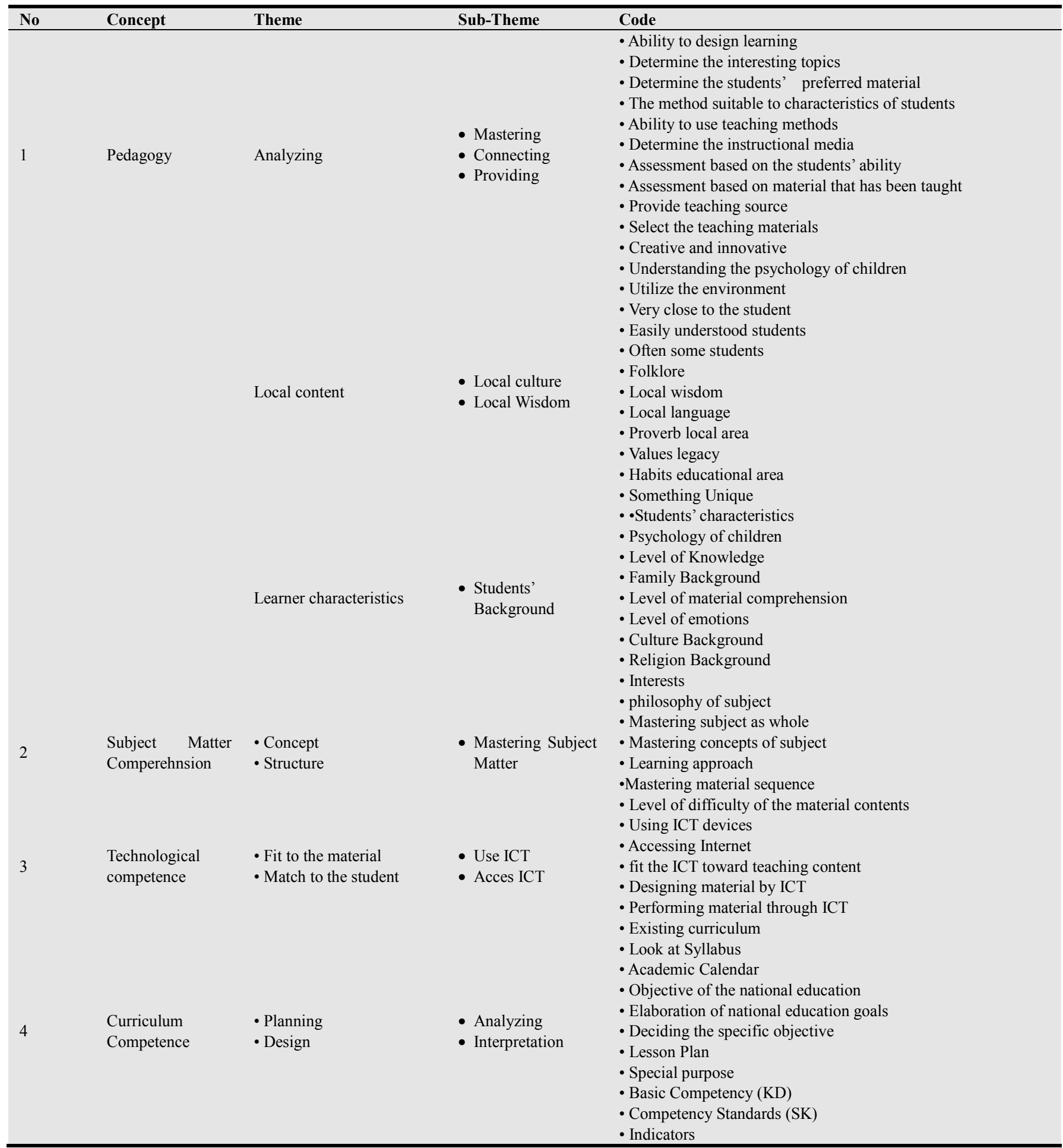

\section{Conclusion}

The result of our research proposed the competences needed by secondary schools' teacher in designing insteruction, as follows: subject matter comprehension, pedagogical competence, technological competence, and curriculum competence. Majority of the respondents believes that fourth major competence become a set up body of knowledge and skill that will lead teacher in formulating a well designed intruction. 
The identification of the competences will be useful for the some institutions such, as teachers and schools in performing the effective teaching and learning process, local educational authority and educational institutions might be an additional information and reference in relating to the teacher professional development, the fourth competences can be used as the main focus in the teacher training activities particularly on designing classroom instruction to meet the national education objectives in term of curriculum objectives and student needs.

\section{References}

[1] Stein, M., D. Carnine, and R. Dixon, Intervention in School and Clinic, 199833.

[2] R.Nacino-Brown, F.E. Oke, and D.P. Brown, Curriculum And Instruction: An introduction to methods of teaching. 1982, London: The Macmillan Press Ltd.

[3] Wette, R., Professional knowledge in Action: How experienced ESOL teachers respond to feedback from learners within syllabus and contextual constraints. System, 2010. 38: p. 569-579.

[4] Kurt D. Squire, et al., Designed Curriculum and Local Culture: Acknowledging the Primacy of Classroom Culture. Wiley InterScience 2003. 87: p. pp.468 - 489.

[5] Chang, M.C., Mendukung Reformasi Guru di indonesia. 2010, Bank Dunia: Jakarta.

[6] Hill, H.C., B. Rowan, and D.L. Ball, Effects of Teachers' Mathematical Knowledge for Teaching on Student Achievement American Educational Research Journal, 2005. vol. 42: p. pp. 371-406.

[7] Rockoff, J.E., The Impact of Individual Teachers on Student Achievement: Evidence from Panel Data. The American Economic Review, 2004. vol. 94: p. pp. 247-252.

[8] Stronge, J.H., T.J. Ward, and L.W. Grant, What Makes Good Teachers Good? A Cross-Case Analysis of the Connection Between Teacher Effectiveness and Student Achievement. Journal of Teacher Education, 2011. vol.62: p. pp.339-355.

[9] Freeman, D.J. and A.C. Porter, Do The Textbook Determine the Content of Math Instruction in Elementary Schools? American Educational Research journal, 1989. 26: p. 403-421.

[10] Sosniak, L.A. and C.L. Perlman, Secondary Education by the Book. Journal of Currriculum Studies, 1990. 22: p. 427-442.

[11] Stodolsky, The Subject Matters. 1989, Chicago: University of Chicago Press.

[12] Zais, R.S., Curriculum Principles and Foundations. 1976, New York: Thomas Y. Crowell Company, Inc.
[13] Davis, E.A. and J.S. Krajcik, Designing Educative Curriculum Materials to Promote Teacher Learning. Educational Researcher, 2005. Vol. 34: p. pp. 3-14.

[14] Parkay, F.W., E.J. Anctil, and G. hass, Curriculum Planning: A Contrary Approach. 8 ed. 2006, United States: Pearson Education, Inc.

[15] Ho, D.C.W., Teacher Participation in Curriculum and Pedagogical Decisions: Insights into Curriculum Leadership. Educational Management Administration \& Leadership, 2010. 38: p. pp.613-624.

[16] Rio Sumarni, S., Design of Instructional Materials for Teaching and Learning Purposes: Theory Into Practice. MEDC, 2007. vol. 1: p. pp. 97- 110.

[17] Witzel, B.S. and P.J. Riccomini, Optimizing Math Curriculum to Meet the Learning Needs of Students. Preventing School Failure. Alternative Education for Children and Youth, 2007. vol. 52: p. pp. 13-18.

[18] Shakir, M., H.D. Aslam, and M.B. Habib, An Evaluation of Secondary School Teachers' Subject Knowledge Competency International Journal of Learning \& Development, 2012. vol.2: p. pp.232-240.

[19] Fishman, B., et al., Linking Teacher and Student learning to Improve Professional Development in Systemic Reform. Teaching and Teacher Education 2003. vol.19: p. pp.643-658.

[20] Garbett, D., Developing Pedagogical Practices to Enhance Confidence and Competences in Science Education. Journal Science Teacher Education, 2011. vol.22: p. pp.729-743.

[21] Pop, M.-C. and C.-A. Mazilescu, Competence-based curricular design for foreign language teaching in the Romanian Technical Universities. Procedia - Social and Behavioral Sciences, 2012. vol. 46: p. pp. 4200 - 4204.

[22] Bantwini, B.D., How teachers perceive the new curriculum reform: Lessons from a school district in the Eastern Cape Province, South Africa. International Journal of Educational Development, 2010. vol.30: p. pp.83-90.

[23] Law, N., Teacher Skills and Knowledge for Technology Integration. Technology and Learning - Teacher Learning, 2010: p. pp. 211-216.

[24] Yunus, M.M., et al., Pros and Cons of Using ICT in Teaching ESL Reading and Writing. International Education Studies, 2013. Vol. 6.

[25] Beauchamp, G. and S. Kennewell, The Influence of ICT on the Interactivity of Teaching. Educational Information Technology, 2008. 13: p. 305-315.

[26] V., B. and C. V., Using thematic analysis in psychology. Qualitative Research Psychology, 2006. vol.3: p. pp. 77-101. 